\title{
Evaluation on the Efficiency and Ability of Science and Technology Innovation of Beijing City
}

\author{
Dan $\mathrm{Wu}$ \\ North China University of Technology \\ Beijing, China
}

\author{
Jing $\mathrm{Hu}$ \\ North China University of Technology \\ Beijing, China
}

\begin{abstract}
The regional science and technology innovation efficiency is an important basis to improve the regional science and technology innovation ability. Referencing to the results of the available literatures at home and abroad, we take the science and technology innovation ability in Beijing city as the research object. On one hand, the DEA model and super-efficiency DEA model are adopted to measure the static efficiency of input and output in the science and technology innovation of Beijing city. On the other hand, the Malmquist index model is used to measure the dynamic efficiency of the input and output in the science and technology innovation of Beijing city. At the meantime, the principal component-ideal solution model is built to evaluate the science and technology innovation ability of Beijing city. On this basis, according to the static and dynamic efficiency of the input and output of science and technology innovation and the science and technology innovation ability of Beijing, the correlation degree between the two is evaluated, and the relevance between static and dynamic efficiency of the input and output of science and technology innovation of Beijing city and its science and technology innovation ability is diagnosed, and the countermeasures and suggestions for the further improvement of the input and output efficiency of the science and technology innovation of Beijing city are proposed. The research results show, the input and output efficiency of the science and technology innovation of Beijing city fluctuates during 1996 and 2014, with most of the effective years. Except for several years, Beijing city has basically realized the continuous improvement of the technical progress and the science and technology innovation ability. The changes of the static and dynamic input and output efficiency of the science and technology innovation of Beijing are similar to that of the science and technology innovation ability. The degrees of association between them reach 0.976 and 0.998 respectively. Although the overall situation of the science and technology innovation efficiency of Beijing city during 1996 and 2014 is good, some problems still exist: the redundant science and technology input and the inadequate output prevail in the years with a low technical efficiency. The input index of the science and technology innovation is redundant. The inadequate output of science and technology innovation shows in the patent index. It shows the resource utilization rate of the science and technology innovation of Beijing city is low, and the capability of independent innovation remains to be further improved.
\end{abstract}

Keywords—science and technology innovation; static efficiency;

Youth Project of National Natural Science Foundation of China (71603004), Youth Project of Beijing Social Science Fund (17GLC064), Outstanding Young Talent Training Plan Project of North China University of Technology (XN018035) dynamic efficiency; ability; evaluation

\section{INTRODUCTION}

To significantly enhance china's independent innovation ability and strengthen the influence of science \& technology investment on eco-social development, Chinese government has put forward two kinds of science \& technology growth way: extensive growth and connotative growth. The extensive way means increasing investment in science $\&$ technology and the connotative way means improving the scientific \& technological innovation efficiency. As the national science \& technology center, Beijing has the best quality resources of science \& technology, and should focus on science \& technology innovation efficiency if it wants to improve its innovation ability in the future. Therefore, the paper measures Beijing scientific \& technological innovation efficiency, then analyses the relationship between scientific \& technological innovation efficiency and scientific \& technological innovation ability to evaluation the innovation level systematically and find out its internal problems, and explore the corresponding countermeasures and suggestions.

\section{LITERATURE REVIEW}

The government of our country proposes the extended growth and the connotative development to remarkably strengthen the capability of independent innovation of our country, improving the promotion of the science and technology input on the economic and social development and promoting the change of the economic growth pattern. The extended growth mainly shows in intensifying the science and technology input. The connotative development means improving the science and technology innovation efficiency and the science and technology innovation ability on the basis of intensifying the science and technology input. The regional science and technology innovation efficiency and the ability evaluation belong to the two key technical issues of the evaluation on the science and technology innovation. As the important contents to accelerate the connotative development of science and technology, it has become the popular issues among scholars at home and abroad.

For the evaluation on the science and technology innovation efficiency, the key technology is to analyze the influence factors of the input and output of the regional science and technology innovation and measure the input and output efficiency of science and technology innovation. The influence 
factors of the input of science and technology innovation involve the science and technology human input such as the people in scientific and technological activities, R\&D personnel, scientists and engineers, and the financial investment of science and technology like the funds for the scientific and technological activities and R\&D funds; the influence factors of the output of science and technology innovation mainly involve the direct output of patent and paper and the indirect output of the volume of business on the technology market, new products and the high and new technology industry. According to the existing research results, the measurement of the input and output efficiency of the regional science and technology innovation includes the measurement of static efficiency and dynamic efficiency. The measurement methods mainly include DEA method and its extended model, Malmquist index model and ideal solution [17]. For example, Lee, Hakyeon and Han Ungkyu [1-5] use DEA model to compare the input and output efficiency of the science and technology innovation between different countries like Korea and China, and conduct the Mann-Whitney check and Kruskal Wallis check afterwards; Yu Liping [6] uses DEA model and ideal solution and principal component analysis method to carry out the contrastive analysis on the ranking result of the evaluation on the input and output efficiency of the regional science and technology innovation; Sun Xuhua [7] uses Malmquist index model to conduct the dynamic monitoring of the input and output efficiency of the regional science and technology innovation. In addition, Li Qiang [8] uses the endogenous growth theory to comprehensively evaluate the input and output efficiency of the science and technology innovation in our country and the social and economic effects.

For the evaluation of the science and technology innovation ability, the key point of research is to build the evaluation system of the regional science and technology innovation ability to evaluate the changes of the science and technology innovation ability. According to the existing research results, the evaluation methods of the science and technology innovation ability mainly include gray correlation method, fuzzy evaluation method and TOPSIS method. [9-13] For example, Shi Ping [9] uses the gray correlation method to systematically evaluate the regional science and technology innovation ability of our country, conducting the contrastive analysis on the science and technology ability in different regions; Hu Shuhua [10] uses the fuzzy evaluation method to systematically evaluate the innovation ability of the high and new technology industry of Wuhan city from three dimensions of science and technology, management and system. Ye Wenxian [13] uses comprehensive weight TOPSIS method, DEA method and Malmquist index method to comprehensively evaluate and analyze the coordinated development relation between the science and technology innovation ability and its performance. Besides, Huang Liang [14] uses the catastrophe progression model to conduct the measurement analysis on the science and technology innovation ability of fifty backbone cities of the Yangtze River Economic Zone, reaching the conclusion that the performance of the science and technology innovation between cities is relatively balanced.
According to the results of the existing literature, scholars have conducted the mature research on the evaluation of the science and technology innovation efficiency and the science and technology innovation ability. However, few scholars deeply explore the correlation between the two. Therefore, the static efficiency and the dynamic efficiency of the input and output of the science and technology innovation of Beijing city are measured through using DEA model and super-efficiency DEA model and Malmquist index model, with the science and technology innovation efficiency and ability as the research object. Besides, the science and technology innovation ability of Beijing city is evaluated through building the principal component-ideal solution model. On this basis, according to the static and dynamic input and output efficiency of science and technology innovation and the science and technology innovation ability of Beijing city, evaluate the correlation degree of the two, diagnose the correlation between the input and output efficiency of science and technology innovation and the science and technology innovation ability and propose the countermeasures and suggestions to further improve the input and output efficiency of the science and technology innovation of Beijing city.

\section{RESEARCH DESIGN}

\section{A. Measurement of the Science and Technology Innovation Efficiency}

1) Static efficiency evaluation: The static efficiency of the input and output of the science and technology innovation of Beijing city in different periods is measured through DEA method. And the measure model is shown as follows:

$$
\begin{aligned}
& \min \left[\theta-\varepsilon\left(e^{T} s^{-}+e^{T} s^{+}\right)\right] \\
& \left\{\begin{array}{l}
\sum_{j=1}^{n} \lambda_{j} x_{i j}+s^{-}=\theta x_{i j_{0}} \\
\sum_{j=1}^{n} \lambda_{j} y_{r j}-s^{+}=y_{r j_{0}} \\
\lambda_{j} \geq 0, j=1,2, \cdots, n \\
s^{+} \geq 0, s^{-} \geq 0
\end{array}\right.
\end{aligned}
$$

In formula (1), $\theta$ is the DEA effective value of the static efficiency of the input and output of the science and technology innovation of Beijing city in the period of $j_{0} ; \varepsilon$ is Archimedes infinitesimal; $e$ is unit vector; $s^{-}$and $s^{+}$are slack variables; ${ }^{x_{i j}}$ is the index value of the input index of science and technology innovation of $i$ in Beijing city, $y_{r j}$ is the index value of the output index of science and technology innovation of $r$ in Beijing city; ${ }^{\lambda}$ is the index weight.

According to formula (1), when $\theta=1$ and $s^{-}=s^{+}=0$, the static efficiency of input and output of the science and 
technology innovation of Beijing city in the period of $j_{0}$ is DEA efficiency; when $\theta=1$ and $s^{-} \neq 0$ or $s^{+} \neq 0$, the static efficiency of input and output of the science and technology innovation of Beijing city in the period of $j_{0}$ is weak DEA efficiency; when $\theta<1$, the static efficiency of input and output of the science and technology innovation of Beijing city in the period of $j_{0}$ is DEA inefficiency. The value of the static efficiency measured by this model is within $[0,1]$, and it's impossible to compare the good and bad of the static efficiency value. Therefore, the super-efficiency DEA model is used. The input and output of the science and technology innovation of other units are used to show the input and output of science and technology innovation of the evaluated units, solving the limitation that the static efficiency value is restricted within [0, $1]$.

2) Dynamic efficiency evaluation: The static efficiency of input and output of the science and technology innovation of Beijing city can be reflected through Total Factor productivity Change (TFPch). When the scale return is unchanged, TFPch can be decomposed into Technical Efficiency Change Index (Tech) and Technical Process Change Index (TPch). When the scale return is changeable, the Tech can be further decomposed into the Pure Technical Efficiency Change Index (PEch) and Scale Technical Efficiency Change Index (SEch).

The evaluation model can be shown as follows:

$$
\left\{\begin{array}{l}
\text { TFPch }=T E c h \times T P c h=P E \mathrm{ch} \times S E c h \times T P c h \\
T E c h=\frac{d^{t+1}\left(x_{t+1}, y_{t+1} \mid C, S\right) / d^{+1}\left(x_{t+1}, y_{t+1} \mid V, S\right)}{d^{t}\left(x_{t}, y_{t} \mid C, S\right) / d^{t}\left(x_{t}, y_{t} \mid V, S\right)} \times\left[\frac{d^{t+1}\left(x_{t+1}, y_{t+1} \mid V, S\right)}{d^{t}\left(x_{t}, y_{t} \mid V, S\right)}\right] \\
P E \mathrm{ch}=\frac{d^{t+1}\left(x_{t+1}, y_{t+1} \mid C, S\right) / d^{t+1}\left(x_{t+1}, y_{t+1} \mid V, S\right)}{d^{t}\left(x_{t}, y_{t} \mid C, S\right) / d^{t}\left(x_{t}, y_{t} \mid V, S\right)} \\
S E \mathrm{ch}=\frac{d^{t+1}\left(x_{t+1}, y_{t+1} \mid V, S\right)}{d^{t}\left(x_{t}, y_{t} \mid V, S\right)} \\
T P c h=\left[\frac{d_{i}^{t}\left(x_{t+1}, y_{t+1}\right)}{d_{i}^{t+1}\left(x_{t+1}, y_{t+1}\right)} \times \frac{d_{i}^{t}\left(x_{t}, y_{t}\right)}{d_{i}^{t+1}\left(x_{t}, y_{t}\right)}\right]^{\frac{1}{2}}
\end{array}\right.
$$

In formula (2), TFPch refers to the Total Factor Productivity Change, which measures the dynamic efficiency of input and output of the science and technology innovation of Beijing city: when TEPch $>1$, it means the technical progress exists in Beijing city; when TFPch $<1$, it means the technical recession exists in Beijing; when TFPch $=1$, it means no changes of the technological level of Beijing city appear; Tech represents the variability index of technical efficiency to measure the changes of the relative technical efficiency; TPch represents the variability index of technical progress to measure the changes of the production technology frontier; $x$ and $y$ are the input and output indexes of the science and technology innovation. $d_{i}^{t}\left(x_{t+1}, y_{t+1}\right)$ refers to the level of the input and output efficiency of the science and technology innovation in the period of $t+1$, compared with the decisionmaking unit of $i$ in the period of ${ }^{t}$. PEch represents pure technical efficiency; SEch represents scale efficiency; $S$ represents production possibility set; $C$ represents constant turns to scale, $V$ represents variable return to scale; the $d^{t}\left(x_{t}, y_{t} \mid C, S\right)$ refers to the level of the input and output efficiency of the science and technology innovation in the period of ${ }^{t}$ in the $S$ production possibility set and constant turns to scale. $d^{t}\left(x_{t}, y_{t} \mid V, S\right)$ refers to the level of the input and output efficiency of the science and technology innovation in the period of ${ }^{t}$ in the $S$ production possibility set and variable return to scale.

\section{B. Evaluation on the Science and Technology Innovation Ability}

The principal component-ideal solution model is built to evaluate the science and technology innovation ability of Beijing city. First, use the principal component analysis method to analyze the contribution of the input and output indexes of the science and technology innovation for the principal component factor and conduct the empowerment of the input and output indexes of science and technology innovation. Second, use the ideal solution model to measure the science and technology innovation ability of Beijing city in different periods according to the distances between the indexes of input and output of the science and technology innovation and the positive and negative ideal solutions. The evaluation model is shown as follows:

$$
\begin{gathered}
c_{i}=\frac{d_{i}^{-}}{d_{i}^{+}+d_{i}^{-}}, i=1,2, \mathrm{~L}, m \\
d_{i}^{+}=\sqrt{\sum_{j=1}^{n}\left[\omega_{j}\left(v_{i j}-v_{j}^{+}\right)\right]^{2}}, j=1,2, \mathrm{~L}, n \\
d_{i}^{-}=\sqrt{\sum_{j=1}^{n}\left[\omega_{j}\left(v_{i j}-v_{j}^{-}\right)\right]^{2}}, j=1,2, \mathrm{~L}, n \\
v_{\mathrm{ij}}=\frac{a_{i j}}{\sqrt{\sum_{i=1}^{m} a_{i j}^{2}}}
\end{gathered}
$$

In formula (3), $c_{i}$ refers to the science and technology innovation ability of Beijing city in the period of $i, d_{i}^{+}$and $d_{i}^{-}$are the distances between the input and output indexes of the science and technology innovation of Beijing and the positive ideal solution and the negative ideal solution; $\omega_{j}(j=1,2, \cdots, n)$ refers to the input and output index weight of the science and technology innovation of $j$ determined through the principal component analysis method; $v_{j}^{+}$and $v_{j}^{-}$are the optimal value and the worst value of the input or output index of the science and technology innovation of $j_{\text {respectively; }}{ }^{a_{i j}}$ refers to the input or output 
index value of the science and technology innovation of $j_{\text {in }}$ the period of $i ; v_{\mathrm{ij}}$ is the normalized processing value of $a_{i j}$.

\section{Correlation Analysis of the Science and Technology Innovation Efficiency and Ability}

According to the formulas (1) to (3), the changes of the static and dynamic efficiency of the input and output of science and technology innovation of Beijing city shall conform to the improvement of the science and technology innovation ability of Beijing city. If the static efficiency and the dynamic efficiency of the input and output of science and technology innovation of Beijing city improve, so do the science and technology innovation ability of Beijing city. That's to say, the correlation between the input and output efficiency of science and technology innovation of Beijing city and the science and technology innovation ability of Beijing city is strong, showing the identical development. The evaluation model of the correlation between them is shown as follows:

$$
\left\{\begin{array}{l}
I_{1}=\frac{\sum_{i=1}^{T}\left(\theta_{i} \cdot c_{i}\right)}{\sqrt{\sum_{i=1}^{T} \theta_{i}^{2} \cdot \sum_{i=1}^{T} c_{i}^{2}}} \\
I_{2}=\frac{\sum_{i=1}^{T}\left(\frac{T F P c h_{i+1}}{T F P c h_{i}} \cdot \frac{c_{i+1}}{c_{i}}\right)}{\sqrt{\sum_{i=1}^{T}\left(\frac{T F P c h_{i+1}}{T F P c h_{i}}\right)^{2} \cdot \sum_{i=1}^{T}\left(\frac{c_{i+1}}{c_{i}}\right)^{2}}}
\end{array}\right.
$$

In formula (4), $I_{1}$ is the correlation degree between the static input and output efficiency of science and technology innovation of Beijing city and the science and technology innovation ability of Beijing city. ${ }{ }_{i}$ is the static efficiency of input and output of the science and technology innovation of Beijing city. $c_{i}$ is the science and technology innovation ability of Beijing in the period of $i, I_{2}$ is the correlation degree between the dynamic input and output efficiency of the science and technology innovation of Beijing city and the science and technology innovation ability of Beijing city. TFPCh $_{i}$ and TFPCh $_{i+1}$ are the dynamic efficiency of input and output of the science and technology innovation of Beijing city in the periods of $i$ and $i+1, c_{i+1}$ is the science and technology innovation ability of Beijing in the period of $i+1$.

\section{EMPIRICAL RESEARCH}

The static efficiency and the dynamic efficiency of input and output of the science and technology innovation of Beijing city during 1996 and 2004 are measured respectively through DEA model, super-efficiency DEA model and Malmquist index model. The principal component-ideal solution model is used to measure the science and technology innovation ability of Beijing city during 1996 and 2014, and further evaluate the correlation degree between the two. In consideration of the acquisition of index data, the people involved in the scientific and technological activities of Beijing, the full-time equivalent of $R \& D$ personnel, the internal spending of $R \& D$ funds and the strength of investment of $R \& D$ funds are taken as the input indexes of the science and technology innovation of Beijing city. The patent application quantity of Beijing city, patent authorization quantity, the contract quantity on the technology market and the volume of business of technical contract are taken as the output indexes of science and technology innovation of Beijing city. At the meantime, since the output of science and technology innovation has a hysteresis effect on its input, we set the time lag of science and technology innovation as one year. The input index data of science and technology innovation are from 1996 to 2013, and the output index data of science and technology innovation are from 1997 to 2014.

\section{A. Results of Measuring the Science and Technology Innovation Efficiency}

According to formulas (1) to (2), the results of measuring the static and dynamic efficiency of science and technology innovation of Beijing city during 1996 and 2014 are obtained through Deap2.1, EMS software and EXCEL, as shown in "Table I".

TABLE I. RESUlTS OF MEASURING THE STATIC AND DYNAMIC EFFICIENCY OF SCIENCE AND TECHNOLOGY INNOVATION OF BEIJING CITY DURING 1996 TO 2014

\begin{tabular}{cccclcc}
\hline Year & Crste & Vrste & Scale & $\begin{array}{c}\text { Scale } \\
\text { return }\end{array}$ & $\begin{array}{c}\text { Static } \\
\text { efficiency } \\
\theta_{i}\end{array}$ & $\begin{array}{c}\text { Dynamic } \\
\text { efficiency } \\
\text { TFPch }_{i}\end{array}$ \\
\hline $1996-1997$ & 1.000 & 1.000 & 1.000 & - & $126.99 \%$ & \\
$1997-1998$ & 1.000 & 1.000 & 1.000 & - & $134.79 \%$ & 1.087 \\
$1998-1999$ & 1.000 & 1.000 & 1.000 & - & $103.66 \%$ & 1.045 \\
$1999-2000$ & 1.000 & 1.000 & 1.000 & - & $107.79 \%$ & 1.210 \\
$2000-2001$ & 0.877 & 0.917 & 0.956 & irs & $87.70 \%$ & 0.874 \\
$2001-2002$ & 0.985 & 1.000 & 0.985 & irs & $98.53 \%$ & 1.077 \\
$2002-2003$ & 1.000 & 1.000 & 1.000 & - & $101.40 \%$ & 1.062 \\
$2003-2004$ & 1.000 & 1.000 & 1.000 & - & $108.55 \%$ & 1.098 \\
$2004-2005$ & 0.943 & 0.971 & 0.971 & irs & $94.31 \%$ & 0.990 \\
$2005-2006$ & 1.000 & 1.000 & 1.000 & - & $106.75 \%$ & 1.163 \\
$2006-2007$ & 1.000 & 1.000 & 1.000 & - & $103.71 \%$ & 1.102 \\
$2007-2008$ & 0.999 & 1.000 & 0.999 & irs & $99.93 \%$ & 1.078 \\
$2008-2009$ & 0.911 & 0.935 & 0.974 & irs & $91.11 \%$ & 1.031 \\
$2009-2010$ & 0.949 & 0.951 & 0.998 & drs & $94.91 \%$ & 1.149 \\
$2010-2011$ & 0.956 & 0.957 & 0.999 & drs & $95.58 \%$ & 1.080 \\
$2011-2012$ & 1.000 & 1.000 & 1.000 & - & $100.44 \%$ & 1.134 \\
$2012-2013$ & 1.000 & 1.000 & 1.000 & - & $101.48 \%$ & 1.092 \\
$2013-2014$ & 1.000 & 1.000 & 1.000 & - & $118.53 \%$ & 1.068 \\
\hline
\end{tabular}

In "Table I", crste, vrste and scale is the total efficiency, technical efficiency and scale efficiency of input and output of science and technology innovation respectively. In the column of the scale return, drs, irs and - respectively refer to the progressive decrease of scale return, the progressive increase of scale return and the invariability of scale return. In "Table $1 "$, according to the result of measuring the static efficiency of input and output of science and technology innovation, the result of measuring the overall efficiency of input and output of science and technology innovation of Beijing city during 1996 and 2014 first decreases progressively and then increases progressively. From 1996 to 1998, 2013 to 2014, the input and 
output efficiency of science and technology innovation of Beijing city reaches a high level; from 1998 to 2000, 2002 to 2004, 2005 to 2007 and 2011 to 2013 , the science and technology innovation of Beijing city is effective on the whole; from 2000 to 2002, 2004 to 2005 and 2007 to 2011, the science and technology innovation is ineffective on the whole. According to the evaluation results of the technical efficiency and scale efficiency, from 2001 to 2002 and 2007 to 2008, the overall efficiency of the input and output of science and technology innovation is influenced by the low scale efficiency. At the same time, from 2001 to 2002, 2007 to 2008, the performance of science and technology innovation of Beijing city shows the progressive increase of scale return. It means the input of science and technology innovation is inadequate, leading to the low overall efficiency of the input and output of science and technology innovation. From 2000 to 2001, 2004 to 2005, 2008 to 2011, the technical efficiency and scale efficiency of science and technology innovation of Beijing city jointly influence its overall efficiency.

\section{B. Analysis Results on the Correlation between the Science and Technology Innovation Efficiency and Ability}

According to formulas (3) and (4), the changes of the science and technology innovation efficiency and the science and technology innovation ability of Beijing city from 1996 to 2014 are obtained through Deap2.1, EMS software and EXCEL, as shown in "Table II".

In "Table II", according to the calculation through formula (4), the correlation degree between ${ }^{\theta_{i}}$ and $c_{i}$ is 0.976 , close to the maximum value of 1 . It shows the correlation between $\theta_{i}$ and $c_{i}$ is very strong, and they have the tendency of identical development. "Table I" shows, except for the periods from 2002 to 2003, 2006 to 2007 and 2008 to 2009, the change direction of $\theta$ and $c$ is not convergent, but the change direction of the two in other periods are convergent. Although the change directions of $\theta$ and $c$ in the periods from 2006 to 2007, 2008 to 2009, TFPch increases, making the science and technology innovation ability of Beijing city increase.
TABLE II. CHANGES OF THE SCIENCE AND TECHNOLOGY INNOVATION EFFICIENCY AND THE SCIENCE AND TECHNOLOGY INNOVATION ABILITY OF BEIJING CITY FROM 1996 TO 2014

\begin{tabular}{|c|c|c|c|c|c|c|}
\hline Year & $\begin{array}{c}\begin{array}{c}\text { Static } \\
\text { efficien }\end{array} \\
\text {-cy } \\
\theta_{i}\end{array}$ & $\begin{array}{c}\theta \\
\text { Chan- } \\
\text { ge }\end{array}$ & $\begin{array}{c}\text { Dyna- } \\
\text { mic } \\
\text { efficien } \\
\text {-cy } \\
T F P c h_{i}\end{array}$ & $\begin{array}{c}\text { TFPch } \\
\text { Chan- } \\
\text { ge }\end{array}$ & $\begin{array}{c}\text { Science } \\
\text { and } \\
\text { techno- } \\
\text { logy } \\
\text { innova- } \\
\text { tion } \\
\text { ability } \\
c_{i}\end{array}$ & $\begin{array}{c}c \\
\text { Chan } \\
\text { ge }\end{array}$ \\
\hline $\begin{array}{l}1996- \\
1997\end{array}$ & $126.99 \%$ & & & & 0.381 & \\
\hline $\begin{array}{l}1997- \\
1998\end{array}$ & $134.79 \%$ & Increase & 1.087 & Increase & 0.382 & Increase \\
\hline $\begin{array}{l}1998- \\
1999\end{array}$ & $103.66 \%$ & Decrease & 1.045 & Increase & 0.380 & Decrease \\
\hline $\begin{array}{l}1999- \\
2000\end{array}$ & $107.79 \%$ & Increase & 1.210 & Increase & 0.384 & Increase \\
\hline $\begin{array}{l}2000- \\
2001\end{array}$ & $87.70 \%$ & Decrease & 0.874 & Decrease & 0.369 & Decrease \\
\hline $\begin{array}{l}2001- \\
2002\end{array}$ & $98.53 \%$ & Increase & 1.077 & Increase & 0.374 & Increase \\
\hline $\begin{array}{l}2002- \\
2003\end{array}$ & $101.40 \%$ & Increase & 1.062 & Increase & 0.368 & Decrease \\
\hline $\begin{array}{l}2003- \\
2004\end{array}$ & $108.55 \%$ & Increase & 1.098 & Increase & 0.369 & Increase \\
\hline $\begin{array}{l}2004- \\
2005\end{array}$ & $94.31 \%$ & Decrease & 0.990 & Decrease & 0.355 & Decrease \\
\hline $\begin{array}{l}2005- \\
2006\end{array}$ & $106.75 \%$ & Increase & 1.163 & Increase & 0.359 & Increase \\
\hline $\begin{array}{l}2006- \\
2007\end{array}$ & $103.71 \%$ & Decrease & 1.102 & Increase & 0.373 & Increase \\
\hline $\begin{array}{l}2007- \\
2008\end{array}$ & $99.93 \%$ & Decrease & 1.078 & Increase & 0.372 & Decrease \\
\hline $\begin{array}{l}2008- \\
2009\end{array}$ & $91.11 \%$ & Decrease & 1.031 & Increase & 0.389 & Increase \\
\hline $\begin{array}{l}2009- \\
2010\end{array}$ & $94.91 \%$ & Increase & 1.149 & Increase & 0.441 & Increase \\
\hline $\begin{array}{l}2010- \\
2011\end{array}$ & $95.58 \%$ & Increase & 1.080 & Increase & 0.496 & Increase \\
\hline $\begin{array}{l}2011- \\
2012\end{array}$ & $100.44 \%$ & Increase & 1.134 & Increase & 0.553 & Increase \\
\hline $\begin{array}{l}2012- \\
2013\end{array}$ & $101.48 \%$ & Increase & 1.092 & Increase & 0.601 & Increase \\
\hline $\begin{array}{l}2013- \\
2014\end{array}$ & $118.53 \%$ & Increase & 1.068 & Increase & 0.616 & Increase \\
\hline
\end{tabular}

Note: The increase of $\theta$ means the static efficiency of this period is larger than that of the last period, and the decrease of $\theta$ means the static efficiency of this period is smaller than that of the last period. The increase of the dynamic efficiency TFPch means TFPch $>1$, and the decrease of the dynamic efficiency TFPch means TFPch $<1$. The increase of $c$ means the science and technology innovation ability of this period is larger than that of the last period, and the decrease of $c$ means the science and technology innovation ability of this period is smaller than that of the last period.

It has been calculated that the correlation degree between the change of TFPch and the change of $c$ is 0.998 , close to the maximum value of 1 , showing the correlation between the change of TFPCh and the change of $c$ is extremely strong and they are inclined to identical development. According to the change of TFPch and the change of $c$, the changes of them in other periods are convergent, except for the periods from 1998 to 1999,2002 to 2003 and 2007 to 2008 . Although the changes 
of them are not convergent during 1998 and 1999, 2007 and 2008, compared with the period from 1997 to 1998, the change of $C_{\text {from }} 1998$ to 1999 can be ignored; compared with the period from 2006 to 2007, the change of $c_{\text {from }} 2007$ to 2008 can be ignored. It shows the change of TFPch and the change of $c$ are convergent. Therefore, on the whole, the dynamic efficiency of input and output of the science and technology innovation of Beijing city conforms to the improvement of the science and technology innovation ability of Beijing city. In conclusion, the science and technology innovation ability of Beijing city will be improved through improving the static and dynamic efficiency of input and output of science and technology innovation of Beijing city.

\section{Results of Redundancy Analysis on the Input and Output of Science and Technology Innovation}

According to "Table I", DEA model is used to conduct the redundancy analysis on the input and output of science and technology innovation for the years with the ineffective input and output of the science and technology innovation of Beijing city, as shown in "Table III".

TABLE III. REDUNDANCY ANALYSIS ON THE INPUT AND OUTPUT OF SCIENCE AND TECHNOLOGY INNOVATION OF BEIJING CITY

\begin{tabular}{|c|c|c|c|c|c|c|}
\hline Year & & Index & $\begin{array}{l}\text { Initial } \\
\text { value }\end{array}$ & $\begin{array}{c}\text { Output } \\
\text { deficiency }\end{array}$ & $\begin{array}{c}\text { Input } \\
\text { redundacy }\end{array}$ & $\begin{array}{l}\text { Discreet } \\
\text { value }\end{array}$ \\
\hline \multirow{8}{*}{$\begin{array}{l}2000- \\
2001\end{array}$} & \multirow{4}{*}{$\begin{array}{l}\text { Output } \\
\text { index }\end{array}$} & Patent application quantity (pc) & 12174 & 354 & 0 & 12528 \\
\hline & & Patent authorization quantity (pc) & 6246 & 238 & 0 & 6484 \\
\hline & & Contract quantity on technology market (item) & 23921 & 0 & 0 & 23921 \\
\hline & & $\begin{array}{l}\text { Volume of business of technical contract (unit:100 million } \\
\text { yuan) }\end{array}$ & 191 & 0 & 0 & 191 \\
\hline & \multirow{4}{*}{$\begin{array}{l}\text { Input } \\
\text { index }\end{array}$} & $\begin{array}{l}\text { People involved in the scientific and technological activities } \\
\text { (uint: } 10 \text { thousand) }\end{array}$ & 261113 & 0 & 24363.10 & 236749.90 \\
\hline & & Full-time equivalent of R\&D personnel (10 thousand per year) & 98723 & 0 & 8144.75 & 90578.25 \\
\hline & & Internal spending of R\&D funds (10 thousand yuan) & 1557011 & 0 & 235767.84 & 1321243.16 \\
\hline & & Investment intensity of R\&D funds $(\%)$ & 4.92 & 0 & 0.94 & 3.98 \\
\hline \multirow{8}{*}{$\begin{array}{l}2004- \\
2005\end{array}$} & \multirow{4}{*}{$\begin{array}{l}\text { Output } \\
\text { index }\end{array}$} & Patent application quantity(pc) & 22572 & 0 & 0 & 22572 \\
\hline & & Patent authorization quantity(pc) & 10100 & 1089 & 0 & 11189 \\
\hline & & Contract quantity on technology market (item) & 37505 & 0 & 0 & 37505 \\
\hline & & Amount of business of technical contract (100 million yuan) & 434.40 & 23.43 & 0 & 457.83 \\
\hline & \multirow{4}{*}{$\begin{array}{l}\text { Input } \\
\text { index }\end{array}$} & $\begin{array}{l}\text { People involved in the scientific and technological activities } \\
\text { (10 thousand) }\end{array}$ & 301202 & 0 & 8681.95 & 292520.05 \\
\hline & & Full-time equivalent of R\&D personnel (10 thousand per year) & 152132 & 0 & 32625.48 & 119506.52 \\
\hline & & Internal spending of R\&D funds (10 thousand) & 3169064 & 0 & 236993.43 & 2932070.57 \\
\hline & & Investment intensity of R\&D funds $(\%)$ & 5.25 & 0 & 0.15 & 5.10 \\
\hline \multirow{8}{*}{$\begin{array}{l}2008- \\
2009\end{array}$} & \multirow{4}{*}{$\begin{array}{l}\text { Output } \\
\text { index }\end{array}$} & Patent application quantity(pc) & 50236 & 398 & 0 & 50634 \\
\hline & & Patent authorization quantity $(\mathrm{pc})$ & 22921 & 3102 & 0 & 26023 \\
\hline & & Contract quantity on technology market (item) & 49938 & 0 & 0 & 49938 \\
\hline & & Amount of business of technical contract (100 million yuan) & 1236 & 0 & 0 & 1236 \\
\hline & \multirow{4}{*}{$\begin{array}{l}\text { Input } \\
\text { index }\end{array}$} & $\begin{array}{l}\text { People involved in the scientific and technological activities } \\
\text { ( } 10 \text { thousand) }\end{array}$ & 450147 & 0 & 29099.64 & 421047.36 \\
\hline & & Full-time equivalent of R\&D personnel (10 thousand per year) & 200080 & 0 & 28874.32 & 171205.68 \\
\hline & & Internal spending of $R \& D$ funds ( 10 thousand) & 6200983 & 0 & 807688.62 & 5393294.38 \\
\hline & & Investment intensity of R\&D funds $(\%)$ & 5.58 & 0 & 0.36 & 5.22 \\
\hline \multirow{8}{*}{$\begin{array}{l}2009- \\
2010\end{array}$} & \multirow{4}{*}{$\begin{array}{l}\text { Output } \\
\text { index }\end{array}$} & Patent application quantity (pc) & 57296 & 8972 & 0 & 66268 \\
\hline & & Patent authorization quantity (pc) & 33511 & 0 & 0 & 33511 \\
\hline & & Contract quantity on technology market (item) & 50847 & 0 & 0 & 50847 \\
\hline & & Amount of business of technical contract (100 million yuan) & 1579.50 & 0 & 0 & 1579.50 \\
\hline & \multirow{4}{*}{$\begin{array}{l}\text { Input } \\
\text { index }\end{array}$} & $\begin{array}{l}\text { People involved in the scientific and technological activities } \\
\text { (10 thousand) }\end{array}$ & 529985 & 0 & 52726.22 & 477258.78 \\
\hline & & Full-time equivalent of R\&D personnel (10 thousand per year) & 191779 & 0 & 9325.12 & 182453.88 \\
\hline & & Internal spending of R\&D funds (10 thousand yuan) & 6686351 & 0 & 325119.02 & 6361231.98 \\
\hline & & Investment intensity of R\&D funds $(\%)$ & 5.50 & 0 & 0.39 & 5.11 \\
\hline \multirow{8}{*}{$\begin{array}{l}2010- \\
2011\end{array}$} & \multirow{4}{*}{$\begin{array}{l}\text { Output } \\
\text { index }\end{array}$} & Patent application quantity(pc) & 77955 & 6354 & 0 & 84309 \\
\hline & & Patent authorization quantity(pc) & 40888 & 4203 & 0 & 45091 \\
\hline & & Contract quantity on technology market (item) & 53552 & 0 & 0 & 53552 \\
\hline & & Amount of business of technical contract (100 million yuan) & 1890 & 0 & 0 & 1890.30 \\
\hline & \multirow{4}{*}{$\begin{array}{l}\text { Input } \\
\text { index }\end{array}$} & $\begin{array}{l}\text { People involved in the scientific and technological activities } \\
\text { (10 thousand) }\end{array}$ & 529811 & 0 & 28453.46 & 501357.54 \\
\hline & & Full-time equivalent of $R \& D$ personnel (10 thousand per year) & 193718 & 0 & 8335.11 & 185382.90 \\
\hline & & Internal spending of R\&D funds (10 thousand yuan) & 8218234 & 0 & 512008.76 & 7706225.25 \\
\hline & & Investment strengthen of R\&D funds (\%) & 5.82 & 0 & 0.25 & 5.57 \\
\hline
\end{tabular}

"Table III" shows the input of science and technology innovation is redundant in the years with a low technical efficiency. The output deficiency exists in every year to a certain extent, mainly in the aspect of patent.
- The patent index with output deficiency from 2004 to 2005 only involves patent authorization quantity, and the patent index with output deficiency from 2009 to 2010 only involves patent application quantity. 
However, the patent index with output deficiency from 2000 to 2001, 2008 to 2009 and 2010 to 2011 covers the patent application quantity and the patent authorization quantity;

- Except for patent index, the index with output deficiency has the volume of business of technical contract. The ideal value of the volume of business of technical contract from 2004 to 2005 is 45.783 million yuan, which is 2.343 billion yuan higher than the real number.

\section{CONCLUSION}

The input and output efficiency of the science and technology innovation of Beijing and the science and technology innovation ability from 1996 to 2014 are evaluated. The research result shows the correlation degrees of the static and dynamic efficiency of input and output of science and technology innovation of Beijing city and the science and technology innovation ability are 0.976 and 0.998 respectively, which are close to the maximum value of 1 ; the changes of the static and dynamic input and output efficiency of the science and technology innovation of Beijing city are basically similar to the change of the science and technology innovation ability of Beijing city. The continuous improvement of the technical progress and the science and technology innovation ability is realized, except for several years. However, the input and the output of science and technology innovation of Beijing city are still redundant to a certain extent. According to the above analysis results, the following suggestions are proposed: 1) Improve the science and technology innovation ability of Beijing city from the perspective of efficiency, turn from the extended growth of science and technology to the connotative development of science and technology and dynamically monitor the static efficiency and the dynamic efficiency of input and output of the science and technology innovation. At the same time, the strong impetus of the technical efficiency on the scientific and technological progress can be used. On one hand, we can give full play to the scientific research function and the innovation ability of scientific research institutions and universities and timely adjust the input direction of the scientific and technological resources. Meanwhile, we must intensify the science and technology input in the scientific research institutions and universities and optimize the configuration structure of the scientific and technological resources. Related policies can be released to improve the ability of science and technology output and the efficiency of allocating the scientific and technological resources in the period of technological innovation, realizing the steady-state growth of the input and output efficiency of science and technology innovation, in order to improve the science and technology innovation ability; on the other hand, supportive policies like the reduction of taxes and government allocations can be issued to encourage the science and technology innovation of enterprises and strengthen the relation among scientific research institutions, universities and enterprises, promoting the marketization of the innovative achievements of them. In the period of the industrialization of the achievements in scientific research, the efficiency of allocating the scientific and technological resources can be improved to realize the technical innovation with market orientation and cooperation of industry, university and research, and the development with innovation as the main driving force. 2) At the meantime, we must give full play to function of Beijing city as the national science and technology center, improve the configuration structure of scientific and technological resources and improve the efficiency of utilizing the resources of science and technology innovation, dispersing the redundant resources to the surrounding area and improving the configuration efficiency of scientific and technological resources, especially the technical efficiency, at the same time driving the scientific and technological progress of the surrounding areas.

\section{REFERENCES}

[1] Lu, Wen-Min,Kweh, QianLong,Nourani, Mohammad,Huang, FengWen. Evaluating the efficiency of dual-use technology development programsfrom the $\mathrm{R} \& \mathrm{D}$ and socio-economic perspectives[J]. OMEGAINTERNATIONAL JOURNAL OF MANAGEMENT SCIENCE,2016,62:82-92.

[2] Lee, Hakyeon,Park, Yongtae,Choi, Hoogon. Comparative evaluation of performance of national R\&D programs with heterogeneous objectives:ADEAapproach [J]. EUROPEAN JOURNAL OF OPERATIONAL RESEARCH,2009, 196(3):847-855.

[3] Chen, Chiang-Ping, Hu, Jin-Li, Yang, Chih-Hai. Produce patents or journal articles? A cross-country comparison of R\&D productivitychange [J]. SCIENTOMETRICS,2013 , 94(3):833-849.

[4] Liu Lei, Hu Shuhua. Comparative Study on the R\&D Management at Home and Abroad and the Enlightenment on the Science and Technology Resource Allocation in China [J], Studies in Science of Science, 2000,18(1):62-66.

[5] Han Ungkyu,Asmild Mette,Kunc Martin. Regional R\&D Efficiency in Korea from Static and Dynamic Perspectives [J]. Regional Studies, 2016, 50(7):1170-1184.

[6] Yu Liping, Xiong Deping, Wu Yishan. Research on the Combination Measurement of Science and Technology Efficiency in Chinese Areas [J], Studies in Science of Science, 2011,29(8):1141-1146.

[7] Sun Xuhua, Chen Shibo, Cheng Guoqiang. Monitoring the Efficiency of the State-owned Science and Technology Resource Allocation Based on Malmquist Index and the Analysis on the Influence Factors [J], Forum on Science and Technology in China, 2011 (3):21-27.

[8] Li Qiang. Research on the Performance Evaluation Model of the Science and Technology Resource Allocation in Our Country Based on the Endogenous Growth Theory [J], Scientific Management Research, 2006,24 (4):93-98.

[9] Li Qian, Shi Ping, Zhao Liyu. Research on the Evaluation of Science and Technology Innovation Ability in Areas of Our Country Based on the Grey Correlation Analysis [J], Science and Technology Management Research, 2010 (2): 43-44.

[10] $\mathrm{Hu}$ Shuhua, Xie Jialong. Evaluation on the Innovation Ability of the High Technology Industry in Wuhan City [J], Journal of Wuhan University of Technology (Information and Management Engineering), 2011(2):258-262.

[11] Zhao Liming. The Evaluation Model of Regional Science and Technology Innovation Ability Based on Entropy Weight TOPSIS and Empirical Research [J], Journal of Tianjin University (Social Science Edition), 2014,16(5): 385-390.

[12] Chen Yanhua. The Empirical Research on the Regional Science and Technology Ability Based on Entropy Weight TOPSIS [J], Industrial Technology and Economy, 2017(5): 46-51.

[13] Ye Wenxian. The Science and Technology Innovation Ability and Performance Evaluation in Xi'an City [J], Science and Technology Management Research, 2017(11): 86-91.

[14] Huang Liang, Wang Zhen, Fan Fei. Measurement and Analysis on the Science and Technology Innovation Ability of Fifty Cities in Yangtze 
River Economic Zone Based on the Catastrophe Progression Model [J], Statistics and Information Forum, 2017(4): 73-80. 